\title{
Intake of wholegrain products and risk of colorectal cancers in the Diet, Cancer and Health cohort study
}

\author{
R Egeberg*,', A Olsen', S Loft ${ }^{2}$, J Christensen', NF Johnsen', K Overvad ${ }^{3,4}$ and A Tjønneland' \\ 'Institute of Cancer Epidemiology, The Danish Cancer Society, Strandboulevarden 49, DK-2 I 00 Copenhagen $\emptyset$, Denmark; ${ }^{2}$ Institute of Public Health, \\ University of Copenhagen, Øster Farimagsgade 5, PO box 2099, DK-1014 Copenhagen K, Denmark; ${ }^{3}$ Department of Epidemiology, School of Public \\ Health, Aarhus University, Bartholins Allé 2, DK-8000 Aarhus C, Denmark; ${ }^{4}$ Department of Cardiology, Aalborg Hospital, Aarhus University Hospital, Sdr. \\ Skowej 15, DK-9000 Aalborg, Denmark
}

BACKGROUND: Consumption of wholegrain (WG) products may protect against colon and rectal cancer.

METHODS: The associations between total and individual WG product consumption and colon and rectal cancer risk were prospectively examined using data on $46 \mathrm{I}$ incident cases of colon cancer and 283 incident cases of rectal cancer that developed during 10.6 years (median) of follow-up among 26630 men and 29189 women taking part in the Diet, Cancer and Health cohort. Incidence rate ratios (IRRs) of colon and rectal cancer related to total or individual WG product intake were calculated using Cox regression.

RESULTS: Higher WG product intake was associated with lower risk of colon cancer and rectal cancer in men. The adjusted IRR (95\% Cl) was 0.85 (0.77-0.94) for colon cancer and $0.90(0.80-1.01)$ for rectal cancer per daily $50 \mathrm{~g}$ increment in intake. For colon cancer the association was confined to intake of WG bread in particular. No consistent associations between total or individual WG product consumption and colon or rectal cancer risk were observed in women.

CONCLUSION: The findings suggest that higher total WG product intake is associated with a lower risk of colon and perhaps rectal cancer in men, but not in women.

British Journal of Cancer (2010) 1 03, 730-734. doi:10.1038/sj.bjc.6605806 www.bjcancer.com

(C) 2010 Cancer Research UK

Keywords: wholegrain products; colon cancer; rectal cancer; prospective study

Wholegrain (WG) products are widely recommended as part of a healthy diet in many countries, but their significance for cancer prevention is not understood. With respect to colon and rectal cancer, a preventable effect of WG products seem plausible as they are rich in a variety of components including dietary fibres and other bioactive substances such as vitamins (vitamins belonging to the B group and vitamin E), minerals (e.g. magnesium, selenium), antioxidants, phytooestrogens and other phytochemicals which all are anticipated to influence cancer risk through various mechanisms (Slavin, 2004).

Although much data from case-control studies are supportive of a protective association between WG product intake and colorectal cancer risk (Jacobs et al, 1998; Levi et al, 1999; La et al, 2003; Slattery et al, 2004), evidence from prospective studies is limited, including two studies showing a protective association (Larsson et al, 2005; Schatzkin et al, 2007) and two showing no overall association (Pietinen et al, 1999; McCullough et al, 2003). Few studies have focussed, as we have, on specific types of WG products, although high intake of rye-based products have been associated with a lower risk of colorectal cancer in some prospective studies (Pietinen et al, 1999; Larsson et al, 2005).

Due to the inconsistent results and limited number of prospective studies, the impact of WG product intake on the risk of colon and rectal cancer is still not clear-cut. Thus, the aim of this

*Correspondence: Dr R Egeberg; E-mail: egeberg@cancer.dk

Received 9 April 2010; revised 15 June 2010; accepted 21 June 2010 study was to examine the association between intake of total and individual WG products in relation to risk of colon and rectal cancer within the Danish Diet, Cancer and Health prospective cohort study. Wholegrain products, especially WG rye bread, are one of the stable foods in Denmark where intake is among the highest in the world. Because of that, the Diet, Cancer and Health study present a unique setting for a study to contribute to the further clarification of any potential role of WG products on risk of colon and rectal cancer. As dietary fibres, one of the proposed components responsible for the potential protective effect of WG products, and colorectal cancer risk has already been examined in the European Prospective Investigation into Nutrition and Cancer (EPIC) (Bingham et al, 2003) (of which the present cohort is part), specific fibre analyses are not included in this study.

\section{SUBJECTS AND METHODS}

The Diet, Cancer and Health study is a prospective cohort study (Tjonneland et al, 2007). In brief, between 1993 and 1997, 160725 Danish men and women were invited to participate, the inclusion criteria being age 50-64 years, living in the greater Copenhagen and Aarhus areas, born in Denmark and not registered with a previous cancer diagnosis in the Danish Cancer Registry (Storm et al, 1997). Subjects were identified by the unique ten-digit identification number, allocated to every citizen by the Danish Central Population Registry, of whom 27178 men and 29875 women participated. All participants attended one of two 
established study centres in Copenhagen and Aarhus. The Diet, Cancer and Health cohort study and the present study were approved by the Regional Ethical Committees on human studies in Copenhagen and Aarhus, and by the Danish Data Protection Agency. The present study is based on data from 26630 male participants and 29189 female participants after exclusion of subjects with a previous cancer diagnosis before baseline $(n=571)$ and subjects who did not fill in the lifestyle questionnaire $(n=37)$. In addition, we further excluded 285 men and 341 women because of missing information on variables considered in the analyses.

Diet was measured by a 192-item food frequency questionnaire (FFQ) that each cohort participants received by mail before their visit to one of the two study centres. A description of the development and validation of this FFQ has been published previously (Overvad et al, 1991; Tjonneland et al, 1991, 1992; Haraldsdottir et al, 1994). The FFQ was designed specifically for the study population, aiming to capture the average intake of different food and beverage items over the past 12 months before study inclusion. Dietary consumption was assessed in 12 categories of predefined responses, ranging from 'never' to '8 times or more per day'. Daily intakes of foods and nutrients were calculated for each participant by the software programme FoodCalc (www.ibt.ku.dk/jesper/foodcalc/) using population-specific standardised recipes and portion sizes. We considered total daily intake (g per day) of WG products as the main exposure variable. This food group consisted of intake of WG rye bread, WG bread and oatmeal. Secondary analyses were conducted for the three individual WG products (WG rye bread, WG bread and oatmeal).

During the study centre visit, participants also completed a lifestyle questionnaire including questions regarding social factors, health status, reproductive factors and lifestyle habits. From this questionnaire the following information was available: years of school education, use of hormone replacement therapy (HRT) and leisure time physical activity. The FFQ and the lifestyle questionnaire were both processed during the visit by optical scanning and checked so that missing or unclear information could be clarified with the participant before he/she left the study clinic. A few missing values were accepted in the lifestyle questionnaire, but not in the FFQ. Furthermore, participants had their anthropometrical measurements (e.g., height and weight) recorded by trained health professionals at the study clinics. Body mass index (BMI) was calculated as weight $(\mathrm{kg})$ per height ${ }^{2}\left(\mathrm{~m}^{2}\right)$.

All cohort members were linked to the Central Population Registry for information on vital status and emigration. Each cohort member was followed up for colon or rectal cancer from the date of entry, that is, date of visit to the study centre until the date of diagnosis of any cancer (except non-melanoma skin cancer), the date of death, date of emigration or 27 April 2006. Information on cancer incidence was obtained by linkage to the Danish Cancer Registry using the personal identification number of each participant. All individuals in Denmark who are diagnosed with cancer are registered herein using the Central Population Registry system (Storm et al, 1997). Definition of colon and rectal cancer was based on the tenth Revision of the International Classification of Diseases. Cancers of the colon included tumours occurring at the colon (C18.0-C18.9 and C19). Proximal colon tumours included the caecum, appendix, ascending colon, hepatic flexure, transverse colon and splenic flexure (C18.1-C18.5). Distal colon tumours included the descending (C18.6) and sigmoid (C18.7) colon and tumours occurring at the rectosigmoid junction (C19.9). Colon tumours at overlapping lesions (C18.8) and colon NOS (C18.9) were grouped among all colon cancers only. Rectal cancers included tumours occurring at the rectum (C20). Anal canal tumours were not considered in this analysis.

\section{Statistical analysis}

The analyses of the relation between the WG product variables and colon or rectal cancer rates were based on the Cox proportional hazard model (including time-dependent variables) using age as the time axis to ensure that the estimation procedure was based on comparisons of individuals at the same age, which allowed for age adjustment to prevent confounding by age. The other time variable, time under study, was included as a time-dependent variable modelled by a linear spline with a boundary at 1,2 and 3 years after entry into the study cohort to allow for a possible 'healthy-participants' effect. A linear spline was used because this allows a steady increase in the rate during the first year of follow-up (Greenland, 1995b). Tests of effect modification by sex were performed using the likelihood ratio test. Test for interaction between sex and total WG product intake revealed a significant interaction for both colon $(P=0.0496)$ and rectal cancer $(P=0.0008)$. Consequently, data were analysed separately by sex.

All models were adjusted for baseline values of potential colon or rectal cancer risk factors including BMI (weight $(\mathrm{kg})$ per height $(\mathrm{m})^{2}$; continuous), alcohol intake (g per day; continuous), school education (low ( $\leqslant 7$ years), medium ( $8-10$ years) and high $(\geqslant 11$ years)), intake of red and processed meat ( $\mathrm{g}$ per day; continuous) and use of HRT in women only (never, past or current use). Furthermore, colon cancer models were adjusted for leisure time physical activity (includes the six different activities: walking, cycling, sports, housework, gardening and hobby work; the number of activities with participation is defined as $>0 \mathrm{~h}$ per week of activity; continuous) (Johnsen et al, 2006).

All quantitative variables were entered linearly in the Cox model because this is biologically more reasonable than the step functions corresponding to categorisation and, furthermore, it increases the power of the analyses (Greenland, 1995a). The linearity of the associations was evaluated graphically by linear splines with three boundaries placed at the quartiles among cases. As we found no significant departures from linearity, all quantitative variables were entered linearly in the model (Greenland, 1995b).

In the analyses, WG product variables included intakes in grams per day of total WG products and individual WG products (WG rye bread, WG bread and oatmeal). The incidence rate ratios (IRRs) of the associations of linear WG product variables were presented as the IRRs associated with a higher intake of $25 \mathrm{~g}$ per day (individual WG products) or $50 \mathrm{~g}$ per day (total WG products) based on an evaluation of the inter-quartile range among cases (men and women, colon and rectal cancer cases combined). The continuous analyses were further supplemented with categorical analyses. In these categorical analyses, the WG product variables were categorised into quartiles based on the distribution among cases (men and women, colon and rectal cancer cases combined).

Two-sided 95\% confidence intervals (CIs) for the IRRs were calculated based on Wald's test of the Cox regression parameter, that is, on the log rate ratio scale. The procedure PHREG in SAS (release 9.1; SAS Institute, Cary, NC, USA) on a TextPad platform was used for the statistical analyses.

\section{RESULTS}

During a median follow-up of 10.6 years, the distributions of diagnosed cancer cases were as follows: 244 colon cancers (89 proximal, 140 distal and 15 unknown) and 169 rectal cancers in men, and 217 colon cancers (84 proximal, 118 distal and 15 unknown) and 114 rectal cancers in women. Baseline characteristics of the total cohort and cancer cases presented separately for men and women are given in Table 1. Compared with the total cohort of men, male colon and rectal cancer cases had a higher intake of alcohol and red and processed meat and were less educated. Female colon and rectal cancer cases had a lower alcohol intake, were less educated and more likely to be never HRT users compared with the total cohort of women. In addition, colon cancer cases had a slightly higher intake of red and processed meat compared with the total cohort of women. 
Table I Baseline characteristics and wholegrain consumption among the total cohort and colon and rectal cancer cases presented separately for men and women, the Danish Diet, Cancer and Health study

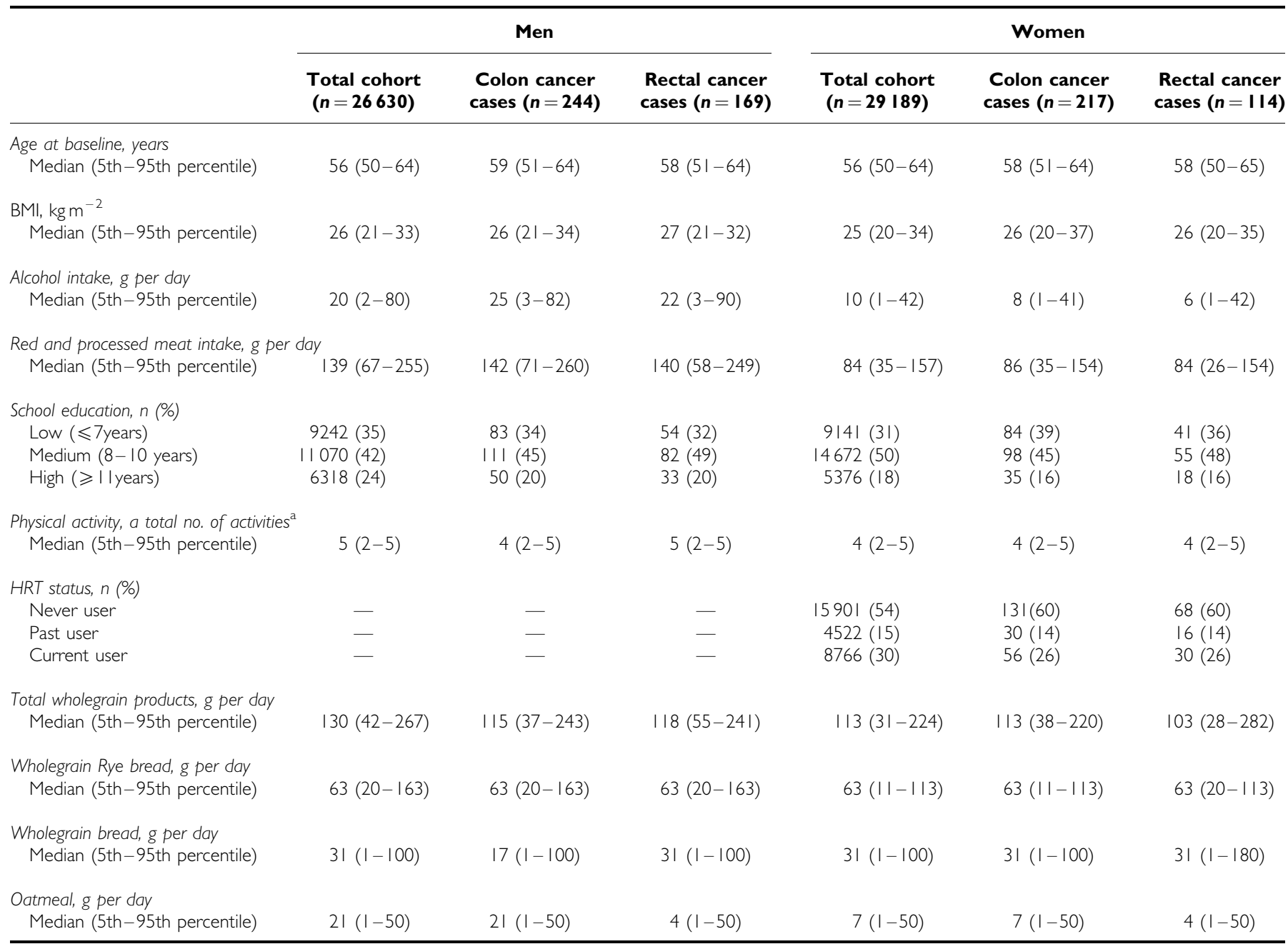

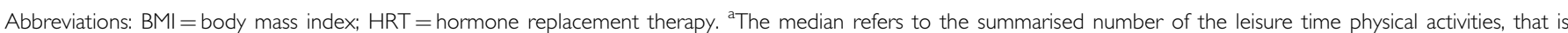
walking, cycling, sports, gardening, housework and do-it-yourself work. Participation is defined as $>0 \mathrm{~h}$ of activity.

Table 2 presents the IRRs $(95 \% \mathrm{CI})$ for colon and rectal cancer according to intake of total and individual WG products in men and women. In men, higher intake of total WG products was associated with a statistically significant $15 \%$ lower incidence rate of colon cancer (IRR 0.85, 95\% CI 0.77-0.94, per each increment in intake of $50 \mathrm{~g}$ per day) and a borderline statistically significant $10 \%$ lower incidence rate of rectal cancer (IRR $0.90,95 \%$ CI $0.80-1.01$, per each increment in intake of $50 \mathrm{~g}$ per day). In women, no consistent associations were observed for either colon or rectal cancer.

Among men, a borderline statistically significant lower risk of colon cancer was found for higher WG rye bread consumption (IRR 0.94, 95\% CI 0.88-1.01). Higher WG bread intake was statistically significantly associated with a lower risk of colon cancer. For every increment in intake of $25 \mathrm{~g}$ per day, the adjusted IRR was 0.89 (95\% CI $0.82-0.97)$. Oatmeal consumption was not associated with the risk of colon cancer among men (Table 2). No associations were found between any of the individual WG products and rectal cancer among men and colon or rectal cancer among women (Table 2).

Among men, intake of total WG products was associated with a lower risk of both proximal and distal colon cancer ( $\mathrm{IRR}_{\text {proximal colon }} 0.78,95 \%$ CI $0.66-0.92$ per each increment in intake of $50 \mathrm{~g}$ per day; $\mathrm{IRR}_{\text {distal colon }} 0.90,95 \%$ CI $0.79-1.02$ per each increment in intake of $50 \mathrm{~g}$ per day). Higher intakes of WG rye bread (IRR $0.89,95 \%$ CI $0.79-1.01$ per each increment in intake of $25 \mathrm{~g}$ per day) and WG bread (IRR $0.88,95 \%$ CI $0.76-1.01$ per each increment in intake of $25 \mathrm{~g}$ per day), but not oatmeal, were borderline statistically significantly associated with lower risk of proximal colon cancer. Only a higher intake of WG bread was associated with a lower risk of distal colon cancer among men (IRR $0.89,95 \%$ CI $0.80-1.00$ per each increment in intake of $25 \mathrm{~g}$ per day). In women, no associations were observed between intake of total or individual WG products and risk of either proximal or distal colon cancer (data not shown).

\section{DISCUSSION}

In this population-based prospective cohort of Danish men and women, we found that higher intake of total WG products was associated with a significant $15 \%$ lower risk of colon cancer, and also a tendency towards lower risk of rectal cancer among men. The association with colon cancer risk among men seemed to be confined to intake of WG bread in particular. We observed no associations of risk of colon or rectal cancer with either total consumption of WG products or with individual types of WG products among women.

The strengths of this study include its prospective design and high follow-up rate, which eliminates potential recall bias or 
Table 2 Incidence rate ratios (IRR) and 95\% Cls for colon and rectal cancer in men and women according to intake of total and individual wholegrain products, the Danish Diet, Cancer and Health study

\begin{tabular}{|c|c|c|c|c|c|c|}
\hline Wholegrain product variables & \multicolumn{3}{|c|}{ Colon cancer } & \multicolumn{3}{|c|}{ Rectal cancer } \\
\hline \multicolumn{7}{|l|}{ Men } \\
\hline $\begin{array}{l}\text { Total wholegrain products (per every } 50 \mathrm{~g} \text { increment) } \\
\text { By categories of daily total wholegrain product intake ( } \mathrm{g} \text { per day) }\end{array}$ & 244 & $0.83(0.76-0.92)$ & $0.85(0.77-0.94)$ & 169 & $0.88(0.79-0.98)$ & $0.90(0.80-1.01)$ \\
\hline Group I: $\leqslant 75$ (g per day) & 61 & 1.00 & 1.00 & 32 & 1.00 & 1.00 \\
\hline Group 4: > 160 (g per day) & 76 & $0.56(0.40-0.78)$ & $0.61(0.43-0.86)$ & 58 & $0.82(0.53-1.26)$ & $0.88(0.57-1.36)$ \\
\hline Wholegrain Rye bread (per every $25 \mathrm{~g}$ increment) ${ }^{d}$ & 244 & $0.93(0.87-1.00)$ & $0.94(0.88-1.01)$ & 169 & $0.96(0.88-1.04)$ & $0.97(0.89-1.05)$ \\
\hline Wholegrain bread (per every $25 \mathrm{~g}$ increment) ${ }^{d}$ & 244 & $0.89(0.82-0.96)$ & $0.89(0.82-0.97)$ & 169 & $0.94(0.86-1.03)$ & $0.95(0.86-1.04)$ \\
\hline Oatmeal (per every $25 \mathrm{~g}$ increment) ${ }^{d}$ & 244 & $0.94(0.77-1.15)$ & $0.95(0.77-1.17)$ & 169 & $0.79(0.61-1.03)$ & $0.80(0.62-1.04)$ \\
\hline \multicolumn{7}{|l|}{ Women } \\
\hline $\begin{array}{l}\text { Total wholegrain products (per every } 50 \mathrm{~g} \text { increment) } \\
\text { By categories of daily total wholegrain product intake (g per day) }\end{array}$ & 217 & $0.96(0.86-1.07)$ & $0.98(0.88-1.10)$ & 114 & $1.01(0.87-1.18)$ & $1.02(0.88-1.19)$ \\
\hline Wholegrain Rye bread (per every $25 \mathrm{~g}$ increment) ${ }^{\mathrm{d}}$ & 217 & $1.01(0.92-1.10)$ & $1.01(0.92-1.11)$ & 114 & $1.04(0.92-1.17)$ & $1.04(0.92-1.18)$ \\
\hline Wholegrain bread (per every $25 \mathrm{~g}$ increment) ${ }^{\mathrm{d}}$ & 217 & $0.96(0.89-1.05)$ & $0.97(0.89-1.06)$ & 114 & $1.04(0.94-1.16)$ & $1.05(0.94-1.16)$ \\
\hline Oatmeal (per every $25 \mathrm{~g}$ increment) ${ }^{\mathrm{d}}$ & 217 & $1.12(0.91-1.38)$ & $1.14(0.92-1.40)$ & 114 & $0.80(0.58-1.11)$ & $0.81(0.58-1.12)$ \\
\hline
\end{tabular}

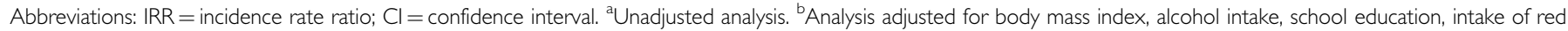

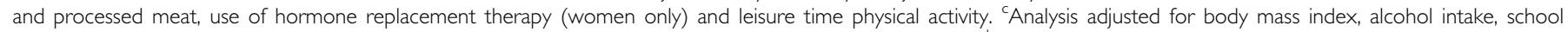
education and intake of red and processed meat and use of hormone replacement therapy (women only). ${ }^{\mathrm{d}}$ The variables were mutually adjusted in analyses.

selection bias; and complete and valid identification of all cancer cases through linkage to the Danish Cancer Registry. Moreover, comprehensive information was also available on potential confounders. Our study also had several potential limitations. First, the relatively small number of both colon and rectal cancer cases, although with more than 10 years of follow-up (median), remains a limitation. This is mainly true for colon cancer subsitespecific analyses and rectal cancer analyses for each sex. Second, although our dietary assessment method is validated (Tjonneland et al, 1991, 1992; Haraldsdottir et al, 1994), some measurement error in the assessment of the dietary intake is inevitable. The use of a self-administered FFQ that, in addition, was not specifically developed to estimate WG product intake among our study population may have contributed to misclassification. This misclassification because of the prospective design of the study is probably non-differential and may have caused an attenuation of results. Finally, although control for potential colon and rectal cancer risk factors in the analyses did not substantially change the estimates, as residual confounding from these variables cannot fully explain the study findings, we cannot exclude the possibility that the study results have been biased by confounding by unaccounted factors.

Four cohort studies have explored associations between total WG product intake and risk of colorectal cancer or its subsites (Pietinen et al, 1999; McCullough et al, 2003; Larsson et al, 2005; Schatzkin et al, 2007). Similar to our findings for men, Schatzkin et al (2007) found in the NIH-AARP Diet and Health study a significant lower risk of colorectal cancer among men for a higher WG intake. In contrast, in two other cohort studies no associations were shown (Pietinen et al, 1999; McCullough et al, 2003). Quite unexpected, intake of total WG products was not associated with risk of either colon or rectal cancer among women in our study. Although these findings agree with results from one previous cohort study (McCullough et al, 2003), they disagree with results from two other recent larger cohort studies presenting results separately for women (Larsson et al, 2005; Schatzkin et al, 2007).
In the Swedish Mammography cohort, Larsson et al (2005) reported a statistically significant lower risk of colon cancer, but not rectal cancer, for highest $v s$ lowest WG product intake. In the above-mentioned NIH-AARP Diet and Health study, there were also indications of lower risk of colorectal cancer for a higher WG intake, although the association was nonsignificant and somewhat weaker than that observed for men in the same cohort (Schatzkin et al, 2007).

It is unclear why our study suggests an association for men but not for women. Possible reasons for the apparent lack of associations between intake of WG products and risk of colon and rectal cancer among women in our study may concern issues regarding lack of sufficient variation in intake of WG products among our female cohort participants to produce an effect, and/or lack of sufficient statistical power in the female-specific analyses, as fewer colon and rectal cancer cases were diagnosed in women than among men. In addition, based on our and the results obtained from the NIN-AARP Diet and Health study, it could be speculated whether the effect of WG products is stronger for men than it is for women. Suggestions of sex-specific effects of other diet-related factors with the development of colon and rectal cancer have been indicated previously (Jacobs, 2007) and what initially motivated us to generally conduct sex-specific analyses. Nonetheless, the gender-specific differences in associations observed in this study require further confirmation.

Small experimental and human intervention studies suggest that in particular WG rye products may hold potential positive effects in relation to colon and rectal cancer prevention that are superior to those of other WG cereals (e.g., WG wheat- and oat-based products; McIntosh et al, 2003; Kallio et al, 2008; Andersson et al, 2010). However, epidemiological data directly examining the effects of different WG products made from different cereal grains (e.g., WG rye, WG wheat and oat) on the risk of colon and rectal cancer are sparse, making comparison of our results with previous studies limited. With regard to specific types of WG products, a lower risk of colon cancer among men was most evident for WG 
bread intake, although a trend towards lower risk of colon cancer with higher consumption of WG rye bread was also apparent. Although this finding was of smaller magnitude in comparison to that of WG bread, it agrees with results from a Finnish cohort study in which a preventive role of rye foods in relation to risk of colorectal cancer in men was also suggested. Although in our study we reported no beneficial effects of WG rye bread intake in women, a significant protective effect of rye bread on risk of colon cancer was observed among women in the Swedish Mammography Cohort (Larsson et al, 2005). Within our cohort it is assumed that the WG bread consumed by our cohort participants is mainly WG wheat based, and thus our data do not strongly indicate differential effects of WG rye- wheat-based products, but this needs confirmation by other studies. In contrast, we did not find that oatmeal intake was associated with the risk of colon or rectal cancer; however, we cannot rule out whether the limited range of intake of oatmeal in our study could have contributed to the null finding for this specific WG product. Future studies should attempt to examine the associations of risk with specific types of WG products.

If colon and rectal cancers are aetiologically distinct (Potter, 1996; Wei et al, 2004), proximal and distal colon cancers can also be considered as different classes of colon cancer (Bufill, 1990; Iacopetta, 2002). Our results showed that higher total WG product consumption was associated with a significant lower risk of proximal colon cancer and an indication of a lower risk of distal colon cancer as well. Although one large case-control study reported no association with proximal or distal colon cancer risk (Hu et al, 2007), our findings are consistent with those of two other prospective studies showing suggestive protective effects of high WG consumption in these cancers (Larsson et al, 2005; Schatzkin et al, 2007). At this point there is no strong indication that a preventive effect of WG product may vary substantially according to specific colon subsite.

In conclusion, we found that a higher intake of total WG products is associated with a lower risk of colon and perhaps also rectal cancer in men, but not in women. Intake of WG bread in particular seemed to account for the association between total WG products and risk of colon cancer in men. Overall, these data, especially for men, provide further support to the public health message to increase the intake of $\mathrm{WG}$ products in gaining optimal health.

\section{ACKNOWLEDGEMENTS}

We thank Katja Boll (data manager), Connie Stripp (dietician) and Jytte Fogh Larsen (project coordinator) for assistance with the data collection and handling.

\section{REFERENCES}

Andersson U, Rosen L, Ostman E, Strom K, Wierup N, Bjorck I, Holm C (2010) Metabolic effects of whole grain wheat and whole grain rye in the C57BL/6J mouse. Nutrition 26: 230-239

Bingham SA, Day NE, Luben R, Ferrari P, Slimani N, Norat $T$, Clavel-Chapelon F, Kesse E, Nieters A, Boeing H, Tjonneland A, Overvad K, Martinez C, Dorronsoro M, Gonzalez CA, Key TJ, Trichopoulou A, Naska A, Vineis P, Tumino R, Krogh V, Bueno-de-Mesquita HB, Peeters PH, Berglund G, Hallmans G, Lund E, Skeie G, Kaaks R, Riboli E (2003) Dietary fibre in food and protection against colorectal cancer in the European Prospective Investigation into Cancer and Nutrition (EPIC): an observational study. Lancet 361: 1496-1501

Bufill JA (1990) Colorectal cancer: evidence for distinct genetic categories based on proximal or distal tumor location. Ann Intern Med 113: 779-788

Greenland S (1995a) Avoiding power loss associated with categorization and ordinal scores in dose-response and trend analysis. Epidemiology 6: $450-454$

Greenland S (1995b) Dose-response and trend analysis in epidemiology: alternatives to categorical analysis. Epidemiology 6: 356-365

Haraldsdottir J, Tjonneland A, Overvad K (1994) Validity of individual portion size estimates in a food frequency questionnaire. Int J Epidemiol 23: 786-796

Hu J, Morrison H, Mery L, DesMeules M, Macleod M (2007) Diet and vitamin or mineral supplementation and risk of colon cancer by subsite in Canada. Eur J Cancer Prev 16: 275-291

Iacopetta B (2002) Are there two sides to colorectal cancer? Int J Cancer 101: $403-408$

Jacobs Jr DR, Marquart L, Slavin J, Kushi LH (1998) Whole-grain intake and cancer: an expanded review and meta-analysis. Nutr Cancer 30: 85-96

Jacobs ET, Thompson PA, Martinez ME (2007) Diet, gender, and colorectal neoplasia. J Clin Gastroenterol 41: 731-746

Johnsen NF, Christensen J, Thomsen BL, Olsen A, Loft S, Overvad K, Tjonneland A (2006) Physical activity and risk of colon cancer in a cohor of Danish middle-aged men and women. Eur J Epidemiol 21: 877-884

Kallio P, Kolehmainen M, Laaksonen DE, Pulkkinen L, Atalay M, Mykkanen H, Uusitupa M, Poutanen K, Niskanen L (2008) Inflammation markers are modulated by responses to diets differing in postprandial insulin responses in individuals with the metabolic syndrome. Am J Clin Nutr 87: 1497-1503

La VC, Chatenoud L, Negri E, Franceschi S (2003) Session: whole cereal grains, fibre and human cancer wholegrain cereals and cancer in Italy. Proc Nutr Soc 62: 45-49

Larsson SC, Giovannucci E, Bergkvist L, Wolk A (2005) Whole grain consumption and risk of colorectal cancer: a population-based cohort of 60,000 women. Br J Cancer 92: $1803-1807$

Levi F, Pasche C, La VC, Lucchini F, Franceschi S (1999) Food groups and colorectal cancer risk. Br J Cancer 79: 1283-1287

McCullough ML, Robertson AS, Chao A, Jacobs EJ, Stampfer MJ, Jacobs DR, Diver WR, Calle EE, Thun MJ (2003) A prospective study of whole grains, fruits, vegetables and colon cancer risk. Cancer Causes Control 14: 959-970

McIntosh GH, Noakes M, Royle PJ, Foster PR (2003) Whole-grain rye and wheat foods and markers of bowel health in overweight middle-aged men. Am J Clin Nutr 77: 967 -974

Overvad K, Tjonneland A, Haraldsdottir J, Ewertz M, Jensen OM (1991) Development of a semiquantitative food frequency questionnaire to assess food, energy and nutrient intake in Denmark. Int J Epidemiol 20: 900-905

Pietinen P, Malila N, Virtanen M, Hartman TJ, Tangrea JA, Albanes D, Virtamo J (1999) Diet and risk of colorectal cancer in a cohort of Finnish men. Cancer Causes Control 10: 387-396

Potter JD (1996) Nutrition and colorectal cancer. Cancer Causes Control 7: $127-146$

Schatzkin A, Mouw T, Park Y, Subar AF, Kipnis V, Hollenbeck A, Leitzmann MF, Thompson FE (2007) Dietary fiber and whole-grain consumption in relation to colorectal cancer in the NIH-AARP Diet and Health Study. Am J Clin Nutr 85: $1353-1360$

Slattery ML, Curtin KP, Edwards SL, Schaffer DM (2004) Plant foods, fiber, and rectal cancer. Am J Clin Nutr 79: 274-281

Slavin J (2004) Whole grains and human health. Nutr Res Reviews 17: 99-110 Storm HH, Michelsen EV, Clemmensen IH, Pihl J (1997) The Danish Cancer Registry-history, content, quality and use. Dan Med Bull 44: 535-539

Tjonneland A, Haraldsdottir J, Overvad K, Stripp C, Ewertz M, Jensen OM (1992) Influence of individually estimated portion size data on the validity of a semiquantitative food frequency questionnaire. Int J Epidemiol 21: 770 - 777

Tjonneland A, Olsen A, Boll K, Stripp C, Christensen J, Engholm G Overvad K (2007) Study design, exposure variables, and socioeconomic determinants of participation in Diet, Cancer and Health: a populationbased prospective cohort study of 57,053 men and women in Denmark. Scand J Public Health 35: $432-441$

Tjonneland A, Overvad K, Haraldsdottir J, Bang S, Ewertz M, Jensen OM (1991) Validation of a semiquantitative food frequency questionnaire developed in Denmark. Int J Epidemiol 20: 906-912

Wei EK, Giovannucci E, Wu K, Rosner B, Fuchs CS, Willett WC, Colditz GA (2004) Comparison of risk factors for colon and rectal cancer. Int J Cancer 108: $433-442$ 